\title{
USO DE DADOS CLIMÁTICOS PARA ANÁLISE ESPACIAL DE RISCO DE INCÊNDIO FLORESTAL
}

\author{
climatic data use for spatial analysis of forest fire risk \\ Keyla Manuela Alencar da Silva Alves* \\ Ranyére Silva Nóbrega**
}

\begin{abstract}
Resumo
O presente artigo tem como objetivo propor uma analise espacial do risco de incêndio florestal através da analise de dados climáticos (precipitação e umidade) em SIG, e aplicação dos mesmos no índice Monte Alegre, desenvolvido no Brasil, o índice possui uma metodologia que diminui o risco à medida que ocorre precipitação, sendo o volume de chuva em $\mathrm{mm}$ considerado para mudança de faixa de perigo. A área escolhida para o estudo é o Parque Nacional do Catimbau, única unidade de conservação nacional continental do estado de Pernambuco. O mesmo encontra-se inserido nos municípios de Buíque, Tupanatinga e Ibimirim. Os resultados obtidos a partir do índice Monte Alegre foram exportados e transformados em mapas na escala de 1:400.000, e correspondem ao ano de 2008. Por fim, este trabalho desenvolveu um resultado de importância substancial para diversas categorias de planejamento e gestão do meio ambiente do Parque Nacional do Catimbau, uma vez que os dados a respeito de incêndios florestais no Parque Nacional do Catimbau são escassos, e para alguns períodos até inexistentes. Esta pesquisa auxiliará a continuidade de estudos futuros em áreas de conservação com tipologias semelhantes.
\end{abstract}

Palavras-chave: Unidade de conservação, SIG, incêndios florestais.

\begin{abstract}
This article objectived a spatial analysis of forest fire risk through the climatic data analysis (precipitation and humidity) in GIS, and implementing Monte Alegre index, developed in Brazil, the methodology index reduces the risk as precipitation occurs, and the volume of rainfall in $\mathrm{mm}$ considered to change the range of danger. National Park Catimbau was area chosen for the study, the only national conservation continental unity of the Pernambuco State. The same is inserted in the Buíque and Tupanatinga Ibimirim cities. Results from Monte Alegre index were exported and transformed into maps on a scale of 1:400,000, and correspond to the year 2008. Finally, this study developed a result of substantial importance for various categories of planning and environmental management of the National Park Catimbau, since the data on forest fires in the National Park Catimbau are scarce, and for some periods of up nonexistent. This research will help the continuity of future studies in conservation areas with similar types.
\end{abstract}

Key words: Conservation unit, GIS, forest fires.

\begin{abstract}
Resumen
Este artículo tiene por objeto proponer un análisis espacial del riesgo de incendios forestales a través del análisis de datos climáticos (precipitación y humedad) en SIG y la aplicación de los mismo en el Índice Monte Alegre, desarrollado en Brasil, el índice cuenta con una metodología que reduce el riesgo cuando ocurrí la precipitación y el volumen de las precipitaciones en mm considera cambiar el rango de peligro. La zona elegida para el estudio es el Parque Nacional Catimbau, la única unidad de conservación nacional continental del estado de Pernambuco. Lo mismo se inserta en las ciudades de Buíque, Ibimirim y Tupanatinga. Los resultados del índice de Monte Alegre se exportaron y se transforma en mapas a escala 1:400.000, y corresponden al año 2008. Por último, este estudio desarrolló un resultado de importancia sustancial para las diversas categorías de planificación y gestión ambiental del Parque Nacional Catimbau, ya que los datos sobre los incendios forestales en el Parque Nacional Catimbau son escasos, y para algunos períodos son inexistentes. Esta investigación ayudará a la continuidad de los estudios futuros en áreas de conservación con tipos similares.
\end{abstract}

Palabras clave: Unidades de Conservación, SIG, Incendios Forestales.

(*) Mestranda do Programa de Pós-Graduação em Geografia Universidade Federal de Pernambuco - Av. Prof. Moraes Rego, 1235 - Cidade Universitária, CEP: 50670-901, Recife (PE) - Brasil, Tél.: (+ 55 81) 2126.8000 - keyla.alencar@yahoo.com

(**) Prof. Dr.do Programa de Pós-Graduação em Geografia Universidade Federal de Pernambuco - Av. Prof. Moraes Rego, 1235 - Cidade Universitária, CEP: 50670-901, Recife (PE) - Brasil, Tél.: (+ 55 81) 2126.8000 - ranyere.nobrega@ufpe.br 


\section{INTRODUÇÃO}

Os incêndios são uma das mais importantes causas de danos aos ecossistemas florestais. Em regiões de desenvolvimento econômico as pressões que as áreas florestais sofrem devido a necessidade de novas zonas destinadas para atividades agropecuárias têm aumentado consideravelmente o numero de incêndios e a extensão de áreas queimadas, devido o mau uso do fogo como ferramenta agrícola (CHUVIECO; MARTÍN, 2004).

Segundo Medeiros (2002), no Brasil os incêndios florestais em Unidades de Conservação (UC) têm ocorrido principalmente por consequência do uso incorreto do fogo por pessoas para renovação de pastagens e limpeza de restos de cultura nas propriedades vizinhas ou até mesmo dentro dos limites de alguns parques. A realização de ações preventivas e a verificação das condições climáticas locais são pouco frequentes, além disso, o período no qual a queimada é empreendida, geralmente é inadequado do ponto de vista climático, o que denota o desconhecimento existente sobre equipamentos de controle do fogo e alternativas ao uso de queimadas.

São também causas corriqueiras a ação de incendiários, caçadores, pescadores e soltura de balões, entre outras. De fato, a ocorrência de grandes incêndios florestais em UC's pode ser considerada uma grave ameaça para a preservação da biodiversidade e manutenção de processos ecológicos. Estes incêndios são particularmente graves para áreas pequenas, sobretudo em ecossistemas muito sensíveis ao fogo, áreas com espécies raras e/ou ameaçadas de extinção. Nestas áreas, há maior possibilidade de que grandes incêndios comprometam a manutenção de populações de algumas espécies.

Destaca-se, como exemplo, em cenário nacional, o incêndio acidental em Roraima no início de 1998 que destruiu cerca de 3,3 milhões de hectares, dos quais mais de 1 milhão de hectares eram cobertos por floresta tropical, representando importantes perdas em termos econômicos e ecológicos.

Atualmente, mesmo com a adoção de medidas de prevenção e monitoramento de incêndios em áreas com cobertura vegetal realizadas por órgãos como INPE (Instituto Nacional de Pesquisas Espaciais), que utilizam imagens de satélite na detecção de queimadas, e IBAMA(Instituto Brasileiro do Meio Ambiente), entre outros órgãos federais, estaduais e municipais, os incêndios ainda são considerados de extrema gravidade. Como exemplo, os incêndios ocorridos na Floresta Nacional de Carajás, em Parauapebas, no sul do Pará, que queimou uma área correspondente a 584 hectares e os registros de 283 focos de fogo (MANZI, 2005).

Nas últimas décadas, com a crescente ocupação e conversão da caatinga em áreas agrícolas, as UC's localizadas neste bioma têm sofrido constantemente os impactos da ação contínua de incêndios florestais (MEDEIROS, 2002). Desta feita, a rapidez e eficiência na detecção e o monitoramento dos incêndios florestais são fundamentais para a viabilização do controle do fogo, redução dos custos nas operações de combate e atenuação dos danos. Além disso, uma informação inadequada da localização do incêndio e extensão da área queimada prejudica a estimativa do impacto do fogo sobre o ambiente.

Batista, Oliveira \& Soares (2002) evidenciaram que o uso de métodos para detecção e monitoramento de incêndios florestais são fundamentais no planejamento do controle, bem como para o dimensionamento dos efeitos produzidos pelo fogo sobre o ambiente.

A redução sistemática dos habitats florestais, provenientes de sucessivos incêndios, tem estimulado o desenvolvimento de novas abordagens para a produção de mecanismos de prevenção, controle e combate ao fogo. A estas, soma-se este trabalho que tem por objetivo identificar espacialmente, por meio de mapas, as áreas de risco de incêndio florestal dentro do Parque Nacional do Catimbau, através do uso de dados climático gerando um produto que auxilie na execução de atividades de prevenção e combate aos incêndios. 


\section{CARACTERÍSTICAS DOS INCÊNDIOS FLORESTAIS}

Os incêndios são classificados em razão do estrato do combustível afetado. Há três tipos de incêndios: de superfície ou superficial, subterrâneo e de copas. Grosso modo, os superficiais propagam-se na superfície do solo, queimando restos vegetais não decompostos até cerca de 2,0 $\mathrm{m}$ de altura. Estes incêndios apresentam propagação rápida, abundância de chamas e liberação intensa de calor. Os subterrâneos propagam-se lentamente através das camadas de húmus ou turfas existentes sobre o solo mineral; apresentam pouca fumaça, sendo, portanto difícil sua detecção e combate. Os incêndios de copas caracterizam-se pela propagação do fogo através das copas das árvores. Geralmente ocorrem a partir dos incêndios superficiais. Propagam-se rapidamente e têm grande poder de destruição (MACEDO; SARDINHA, 1985).

No Brasil, segundo Batista, Oliveira \& Soares (2002), as principais causas de incêndios são: raios, queimada para limpeza de campos agrícolas, operações florestais, fogos campestres, fumantes e incendiários. Já Chuvieco, Salas \& Veja (1997) afirmam que incêndios não programados e não controlados têm consequências diversas em diferentes escalas, que vão desde o risco para as populações rurais até a degradação ambiental, com contribuição para a poluição atmosférica. Entretanto, a extensão e intensidade dos fogos estão relacionadas com diversos fatores, entre os quais o tipo, quantidade e estado de vegetação combustível.

Normalmente, um incêndio começa através de um pequeno foco, que a princípio tende a alastrar-se para todos os lados. Vários fatores, como o vento, declividade do terreno e tipo de combustível definem a forma final dos incêndios que poderá ser circular, irregular ou elíptica (MACEDO; SARDINHA, 1985). O incêndio é formado pela cabeça ou pela frente, que é parte que avança mais rapidamente, queimando com mais intensidade; a cauda, base ou retaguarda, situada em direção oposta à cabeça; os flancos (parte lateral) e ainda pelos fogos secundários (originados pela projeção de partículas incandescentes provindas do fogo principal). De modo geral, o fogo alcança intensidade máxima entre $14 \mathrm{~h}$ e $16 \mathrm{~h}$, o que corresponde à temperatura e à umidade relativa máxima do dia.

\section{ÍNDICE DE INCÊNDIO FLORESTAL}

O índice de risco de incêndios é a medida da probabilidade da ocorrência de incêndios em uma determinada área, sendo resultado de fatores constantes e variáveis, os quais afetam o início, a propagação e a dificuldade de controle de incêndios. Este índice de risco pode ser avaliado e adaptado às regiões de interesse, considerando-se variáveis meteorológicas, tipo de vegetação, topografia e fatores associados ao homem. Um modelo capaz de predizer a ocorrência de incêndios, dia-a-dia, para domínios de interesse, resultaria em controle do incêndio e a distribuição de recursos para a extinção mais eficiente, além de reduzir custos, danos e perdas. O desenvolvimento de um modelo de predição de incêndios sempre apresenta grande dificuldade, principalmente pelas incertezas associadas ao comportamento humano com relação ao fogo (PHILLIPS; NICKEY, 1978).

$\mathrm{O}$ índice de risco de incêndio constitui uma tentativa de quantificar a probabilidade de ocorrência e propagação do fogo quando da existência de uma fonte de ignição. Mutch (1970) define o índice como sendo um termo geral que expressa o resultado da atuação dos fatores constantes e variáveis, os quais afetam as chances de um incêndio iniciar e propagar-se.

O primeiro sistema de índice de previsão de incêndios florestais foi desenvolvido pelo Governo dos Estados Unidos, que integrou as investigações e experiências das diversas organizações federais, estaduais e privadas de combate ao fogo. A organização da proteção em larga escala contra incêndios florestais iniciou-se logo após a criação dos Serviços Florestais dos EUA, integrados ao Ministério da Agricultura. Com o grande incêndio de Idaho em 1905, foi despertada a atenção da opinião pública para a necessidade do desenvolvimento de um sistema de proteção mais eficiente, pelo menos nas florestas nacionais (MACEDO; SARDINHA, 1985).

Gisborne (1936) apresentou a primeira abordagem sistemática sobre o problema da indexação do risco de incêndios. Neste trabalho, ele demonstrou um medidor de risco de incêndio formado 
por uma régua de cálculo em cartão, que correlaciona cinco variáveis e expressam o seu efeito utilizando sete classes de risco. As variáveis utilizadas são: 1) o teor de umidade dos combustíveis, determinado pelo peso de uma vara indicadora; 2) umidade relativa do ar; 3) data desde o início da estação dos incêndios (medindo o estado do combustível e a radiação solar); 4) atividades dos agentes de ignição de fogos (essencialmente faíscas); 5) raio de visibilidade. A régua de Gisborne possuía limitações, pois incluía fatores de inflamabilidade e logísticas difíceis de correlacionar diretamente em uma simples escala numérica. Apenas as três primeiras variáveis (teor de umidade do combustível, umidade do ar e a data) mediam, de fato, a inflamabilidade do combustível. Sampaio (1991) observa que um dos fatores mais importantes, o vento, não foi considerado inicialmente, tendo sido acrescentado posteriormente.

O primeiro trabalho produzido no Brasil que analisou as variáveis meteorológicas para previsão de perigo de incêndio na vegetação foi realizado por Soares (1972) que desenvolveu a fórmula de Monte Alegre (nome da fazenda onde foi realizada a coleta de dados) no Paraná. Para o desenvolvimento da expressão, foram utilizadas as seguintes variáveis meteorológicas: temperatura do ar, umidade relativa do ar, precipitação, déficit de saturação do ar, diferença entre a temperatura do ar e o ponto de orvalho e número de dias sem precipitação maior que $10 \mathrm{~mm}$ (medidas de cinco a trinta dias antes de cada ocorrência de fogo). Foram determinadas as correlações entre as variáveis meteorológicas, a ocorrência de incêndios e as áreas queimadas. Pela análise dos resultados, verificou-se que alguns fatores, como umidade relativa, déficit de saturação do ar e diferença entre a temperatura do ar e o ponto de orvalho correlacionaram de modo mais significativo, enquanto a temperatura do ar mostrou uma correlação muito baixa com a ocorrência de incêndios.

\section{USO DE SIG APLICADO AO RISCO DE INCÊNDIO FLORESTAL}

Nas últimas décadas, várias aplicações de Sistema de Informação Geográfica (SIG) foram desenvolvidas para facilitar a análise espacial do risco de incêndio. No âmbito da prevenção de fogos florestais, o SIG permite a eficiente integração de dados advindos da observação da Terra com fatores geográficos relevantes, tais como a vegetação, topografia e meteorologia (CHUVIECO et al. 1997).

No ambiente do SIG, é possível armazenar, inserir, administrar, analisar e apresentar dados espaciais na forma de mapas, relatórios, gráficos e diagramas. Ainda há a possibilidade de fazer sobreposição de informações e análises espaciais, que são subsídios para a tomada de decisões (OLIVEIRA, 2002).

A rapidez e a eficiência na detecção e monitoramento dos incêndios florestais são fundamentais para a viabilização do controle do fogo, redução dos custos nas operações de combate e atenuação dos danos. Além disso, um conhecimento inadequado da localização do incêndio e extensão da área queimada prejudica a estimativa do impacto do fogo sobre o ambiente (BATISTA, 1999).

Segundo Razafimpanilo et al. (1995), a eficiência do monitoramento de incêndios por satélites vai depender das informações prévias do ambiente, tais como as características do material combustível sobre a regeneração natural e fenologia da vegetação e das condições climáticas.

As características da cobertura vegetal são fatores condicionantes da qualidade e confiabilidade da detecção de incêndios florestais por satélites. Geralmente, em alguns ecossistemas, como as savanas tropicais, um incêndio começa e termina em poucas horas e, portanto, pode ser que se inicie e termine entre dois intervalos de tempos consecutivos do tempo da passagem do satélite, não sendo possível a detecção do incêndio. Já a detecção da área queimada é mais difícil, por causa da assinatura espectral das áreas queimadas que sempre dependem do tipo de cobertura vegetal e das suas condições (BOSCHETTI et al., 2003).

Os avanços recentes na detecção de incêndios incluem o uso dos dados de satélite para avaliar a estação e variabilidade interanual da queimada. Estes novos detalhes permitem uma maior proliferação de informações sobre a ocorrência de incêndios, fazendo com que estes apareçam com frequência nos meios de comunicação. No momento, diferentes avaliações das queimadas da 
biomassa e a sua variabilidade têm sido detectadas em escala regional e global, o que demandará um agrupamento no futuro (BOSCHETTI et al., 2003).

Os testes feitos para relatar o número de ocorrência de fogo detectada sobre uma determinada região e um determinado período do tempo da área queimada, obtidos a partir das imagens de satélite de Along Track Scanning Radiometer (ATSR), Audio-Visual Speech Recogniton (AVSR), AVHRR ou SPOT, mostraram que a correlação entre o número de ocorrência do fogo e área queimada é altamente variável, pois depende do tipo e das condições da vegetação e a época/período do ano. A ocorrência do fogo detectado por sistema de satélite polar orbital tais como National Oceanic and Atmospherie Administration - Advance Very High Resollution Radiometer (NOAA-AVHRR), representa apenas pequenas porções da atividade real do fogo durante o dia. Na verdade, a amostragem mais confiável em todos esses produtos depende de três condições: o período que o satélite passa sobre a área, o que não corresponde ao dia completo; atividade máxima do fogo, e a duração de ocorrência do fogo, que geralmente é curta, o que pode ser de uma hora em algumas regiões, especialmente nos cinturões tropicais (SCHULTZ, 2002).

A expressão "focos de calor" é utilizada para interpretar o registro de calor captado na superfície do solo por sensores espaciais. O sensor AVHRR (advance very high resolution radiometer) capta e registra qualquer temperatura até acima de $47 \mathrm{oC}$ e é possível interpretar como sendo um foco de calor (CHUVIECO; MARTÍN, 2004).

O advento do sistema de informação geográfica (SIG) possibilitou incorporação de outros parâmetros, além do Índice de Vegetação, para gerar um índice de risco de incêndio. Entre os parâmetros que podem ser acrescentados, os principais são: 1) os que variam em curto período de tempo como os dados meteorológicos, de precipitação, umidade relativa e temperatura do ar; 2) os de variação mais esporádica como fitomassa combustível e proximidade de potenciais focos de ignição; 3) os fixos, como topografia. O SIG propicia maior abrangência espacial, dentro de uma abordagem denominada mapeamento de risco, que identifica as regiões com diferentes graus de risco de incêndio, (FERRAZ; VETTORAZZI, 1998).

\section{METODOLOGIA}

A Fórmula de Monte Alegre (FMA), desenvolvida a partir de dados da região central do Paraná, que considera o risco de incêndio florestal como função de duas variáveis: umidade relativa do ar das 13 horas e chuva diária. A Fórmula de Monte Alegre é acumulativa, ou seja, quanto mais longa for à sequência de dias com baixa umidade relativa e sem chuva, maior será o risco climático de incêndio. Dependendo da intensidade da chuva ocorrida, ocorrem abatimentos em seus valores. Quando a chuva diária ultrapassa 12,9 mm, a FMA volta à zero, e o risco é nulo (SOARES, 1972).

O desenvolvimento de um índice de risco de incêndio utiliza um vasto conjunto de fatores, usualmente os combustíveis, a topografia e os meteorológicos. A escolha de variáveis e os diferentes métodos usados para a sua combinação resultam numa multiplicidade de abordagens. Em face desta diversidade, várias soluções para a sua classificação têm sido propostas. Em função dos dados de entrada necessários, dois tipos gerais de métodos podem ser identificados: 1) método de risco estritamente meteorológico, que se baseia exclusivamente em dados sobre o estado das condições atmosféricas (temperatura, umidade relativa, precipitação e intensidade do vento) e 2) método de risco potencial, quando são consideradas abordagens mais avançadas, e inclui como entrada o estado da vegetação, o tipo de combustível e o seu conteúdo de umidade. Dentro do primeiro método, podem-se citar o índice Fórmula de Monte Alegre (SOARES, 1972).

A opção pela FMA se deu exclusivamente por ter sido desenvolvida no Brasil e seguindo uma metodologia que diminui o risco à medida que ocorre precipitação, sendo o volume de chuva em $\mathrm{mm}$ considerado para mudança de faixa de perigo. A determinação do grau de perigo de incêndios pela FMA é feita com base em faixas de valores definidas pelo autor do método Soares (1972), observadas nos Quadros 1 e 2. 
ALVES, K. M. A. da S.; NÓBREGA, R. S.

Quadro 1: Índice de Monte Alegre com relação a precipitação diária

\begin{tabular}{|l|l|}
\hline $\begin{array}{c}\text { CHUVA DO DIA (EM } \\
\text { MM) }\end{array}$ & MODIFICAÇÃO NO CÁLCULO \\
\hline$\leq 2,4$ & Nenhuma \\
\hline 2,5 a 4,9 & Abater $30 \%$ na FMA calculada na véspera e somar $(100 \mathrm{H})$ do dia. \\
\hline 5,0 a 9,9 & Abater $60 \%$ na FMA calculada na véspera e somar $(100 \mathrm{H})$ do dia. \\
\hline 10,0 a 12,9 & Abater $80 \%$ na FMA calculada na véspera e somar $(100 \mathrm{H})$ do dia. \\
\hline$\geq 12,9$ & Interromper o cálculo (FMA = 0) e recomeçar a somatória no dia seguinte. \\
\hline
\end{tabular}

Fonte: ANTUNES, 2000

Quadro 2: Escala de risco de incêndio

\begin{tabular}{|l|l|}
\hline VALOR DE FMA & GRAU DE PERIGO \\
\hline$\leq 1,0$ & Muito pequeno \\
\hline 1,1 a 3,0 & Pequeno \\
\hline 3,1 a 8,0 & Médio \\
\hline 8,1 a 20,0 & Alto \\
\hline$\geq 20,0$ & Muito alto \\
\hline
\end{tabular}

Fonte: ANTUNES, 2000

Os dados utilizados neste trabalhados foram coletados no Parque Nacional do Catimbau. A escolha do Parque como área de pesquisa foi devido à propensão ao fogo no Parque Nacional do Catimbau, caracterizada pela predominância de vegetação de caatinga, que apresenta propriedades xerófitas, juntamente com uma cultura de utilização incorreta de queimadas para manejo agropecuário dentro e fora do perímetro do parque (uma vez que ainda existem comunidades dentro do parque, e tendem a ocasionar incêndios de difícil controle).

Para a aplicação da FMA no Parque Nacional do Catimbau, foram utilizados os dados diários de precipitação e umidade do ar, do Laboratório de Meteorologia de Pernambuco (LAMEPE), das seguintes estações: Ibimirim PCD, Ibimirim (Poço da cruz), Catimbau, Catimbau 1, Tupanatinga, Tupanatinga 1, Buíque, Buíque 1, Buíque 2. (as sete últimas estações foram desativadas em abril de 2009, segundo o LAMEPE, por motivos de força maior). Referente ao período de janeiro de 2008 a dezembro de 2008.

A fórmula de Monte Alegre é dada por:

$\mathrm{n}$

$F M A=\sum_{i=1}\left(100 / H_{i}\right)$

em que:

$\mathrm{FMA}=$ Fórmula de Monte Alegre; $\mathrm{H}=$ umidade relativa do ar $(\%)$, medida às 13 horas e $\mathrm{n}=$ número de dias sem chuva

Sendo acumulativo, o índice está sujeito às restrições de precipitação, como mostra o Quadro 1. A interpretação do grau de perigo estimado pela FMA é também feita através de uma escala proposta por Antunes, 2000, que observamos no Quadro 2.

A partir dai, foram construídos mapas na escala de 1:200.000 para o ano de 2008, separados em dois grupos (de acordo com as características climáticas), assim o primeiro grupo representando o período chuvoso - de março a julho - que corresponderam aos meses de maior precipitação no ano de 2008, o segundo grupo o período seco - de agosto a janeiro (o mês de janeiro por que apresenta taxas de precipitação baixas em comparação aos meses do período chuvoso, sendo assim, 
foi agrupado no período seco deste ano) - que correspondem aos meses de menor precipitação e menor umidade, e maior temperatura. Também foi construído um mapa do FMA anual, com os valores médios, e um mapa com a distribuição espacial do risco de incêndio segundo a escala de classes proposta por Antunes (2000, p.28).

\section{RESULTADOS E DISCUSSÕES}

Os resultados da porção leste do PCN apresentam baixos valores FMA, no período chuvoso (Figura 1), isto por que os índices tanto de precipitação quanto de umidade desta região foram maiores. Os valores FMA variaram entre 10,37 a 15,25, e no período seco os valores foram de 14,65 a 22,55 (Figura 2), são nesta área que estão concentradas as atividades de ação ao combate de incêndios florestais organizada pelo IBMA (Instituto Brasileiro de Meio Ambiente e Recursos Naturais), mas precisamente no distrito de Catimbau - Buíque, isto por que o acesso a esta área é mais fácil (por conta da existência de trilhas ecológicas), e a brigada de combate a incêndios, segundo o IBAMA não dispõem de equipamentos (carro, GPS, torres de observação) suficientes para cobrir todo o PCN, contam com apenas um grupo de 30 pessoas selecionado no próprio distrito de Catimbau para trabalharem no período de risco extremo.

A região central do PCN apresentou valores médios durante o período chuvoso, variaram de 15, 26 a 19,32, isto por que esta região encontra-se inseridos no sertão, que apresenta, historicamente, valores de precipitação e umidade baixos, e de altas temperaturas, isto são características climáticas que não são os objetivos principais deste trabalho detalhá-las, mas é importante ressaltar que estas características influenciam diretamente na avaliação desde índice climático. No período seco os resultados variaram de 22,56 a 27,81, e isto representa um risco médio para o parque.

Foram na parte oeste do PNC onde se obteve os mais altos valores da FMA (Figura 1 e 2). É também a oeste onde há as maiores dificuldades de acesso ao PCN. Os valores variaram de 19,33 a 22,57 , são os maiores valores apresentados durante o período chuvoso, apesar de que se comparados aos valores do período seco $(29,14$ - 34,39), os valores do período chuvoso seria considerados baixos, porém deve-se analisar o risco em que esta área esteve exposta num período especifico. Também se deve considerar o tipo da vegetação, que é denominado como combustível, que neste caso é a caatinga hiperxerófila, e apresenta propriedades favoráveis a incêndios. As propriedades dos combustíveis envolvem o tipo, diâmetro, peso e umidade, dentre as quais o teor de umidade é a mais importante no controle de incêndio (BEUTLING et al., 2005), no entanto não cabe a este trabalho detalhar este fator, já que este estudo se restringe a uma fórmula de fatores climáticos.

O mapa anual (Figura 3), como os demais mapas, apresenta menores valores na região leste e cresce no sentido leste - oeste. Na parte leste os valores variaram de 13,61 a 19,07, e são considerados baixos, apesar de não poder compará-lo com resultados de anos interiores, pois não existem na literatura atual registros do FMA referente ao PNC. E para melhor identificar as áreas de risco de incêndios, aplicou-se ao mapa de valores anual a escala da FMA (Figura 4). 


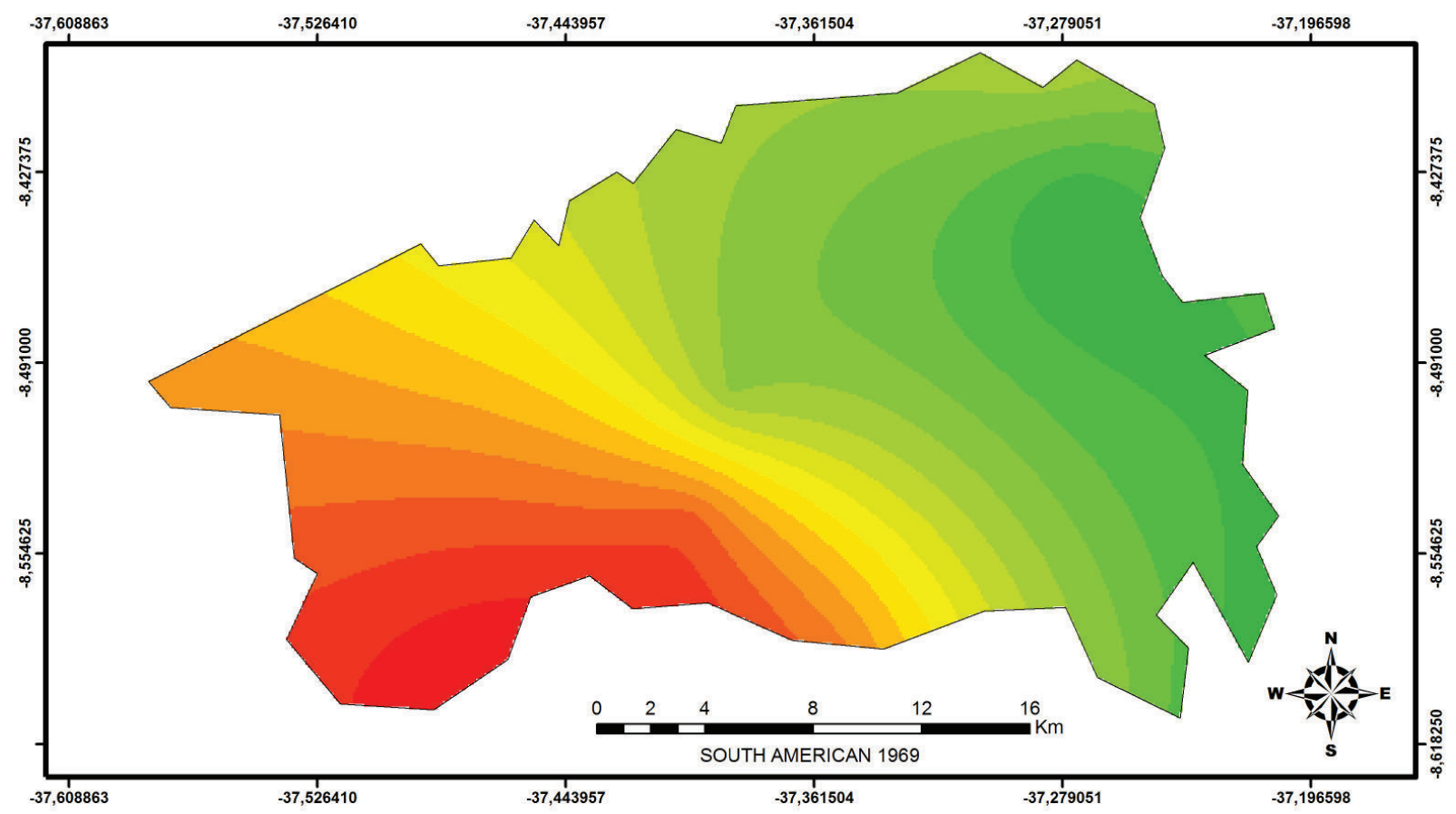

Classes de risco de incêndio - FMA - Período chuvoso

\begin{tabular}{|c|c|c|c|c|}
\hline $10,37-11,18$ & $12,82-13,62$ & $15,26-16,06$ & $17,7-18,5$ & $20,14-20,94$ \\
\hline $11,19-12$ & $13,63-14,44$ & $16,07-16,88$ & $18,51-19,32$ & $20,95-21,76$ \\
\hline $12,01-12,81$ & $14,45-15,25$ & $16,89-17,69$ & $19,33-20,13$ & $21,77-22,57$ \\
\hline
\end{tabular}

Figura 1: Risco de fogo durante o período chuvoso

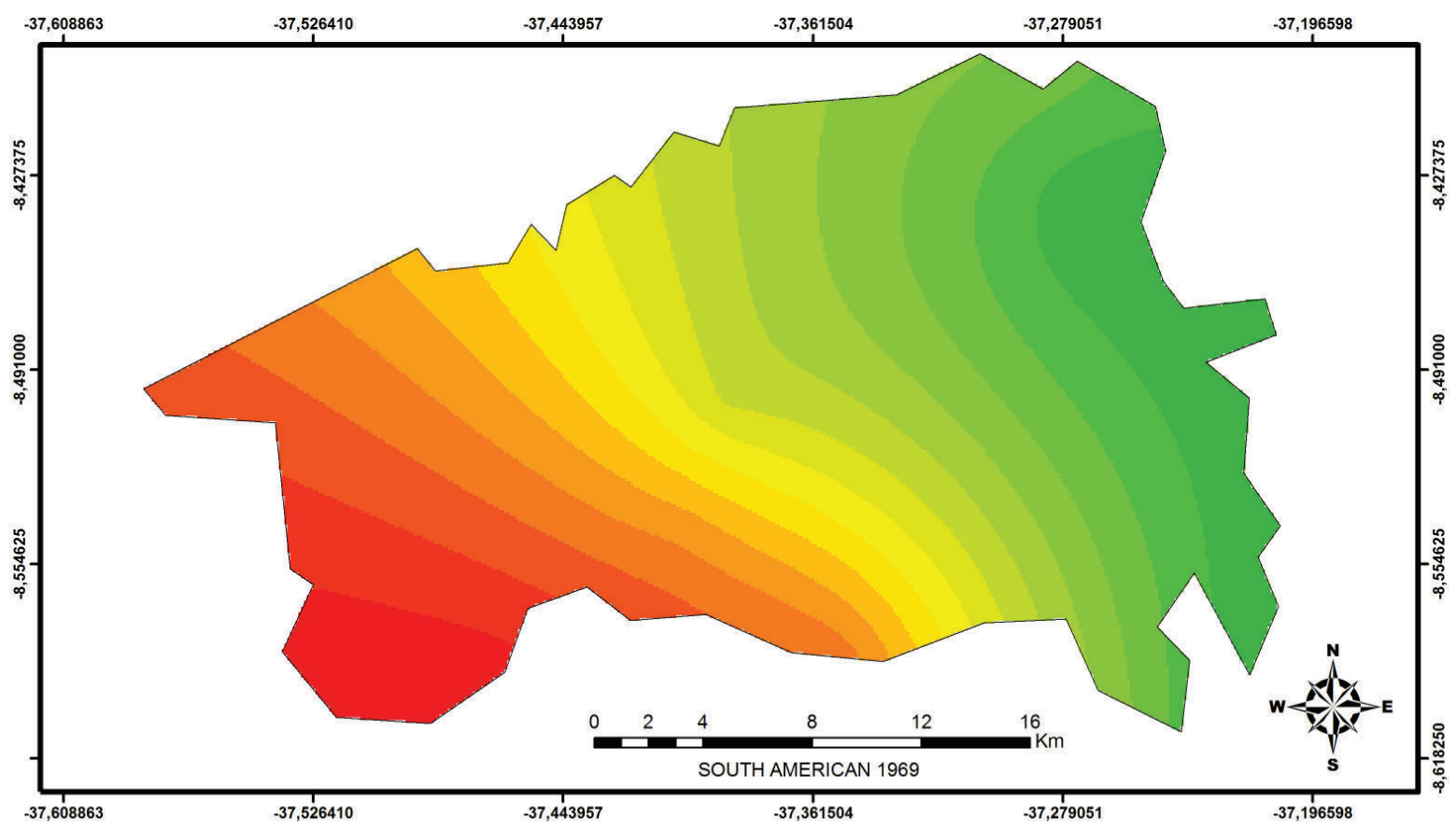

Classes de risco de incêndio - FMA - Período seco

\begin{tabular}{|c|c|c|c|c|}
\hline $14,65-15,97$ & $18,61-19,92$ & $22,56-23,86$ & $26,51-27,81$ & $30,45-31,76$ \\
\hline $15,98-17,29$ & $19,93-21,23$ & $23,87-25,18$ & $27,82-29,13$ & $31,77-33,07$ \\
\hline $17,3-18,6$ & $21,24-22,55$ & $25,19-26,5$ & $29,14-30,44$ & $33,08-34,39$ \\
\hline
\end{tabular}

Figura 2: Risco de fogo no período seco 


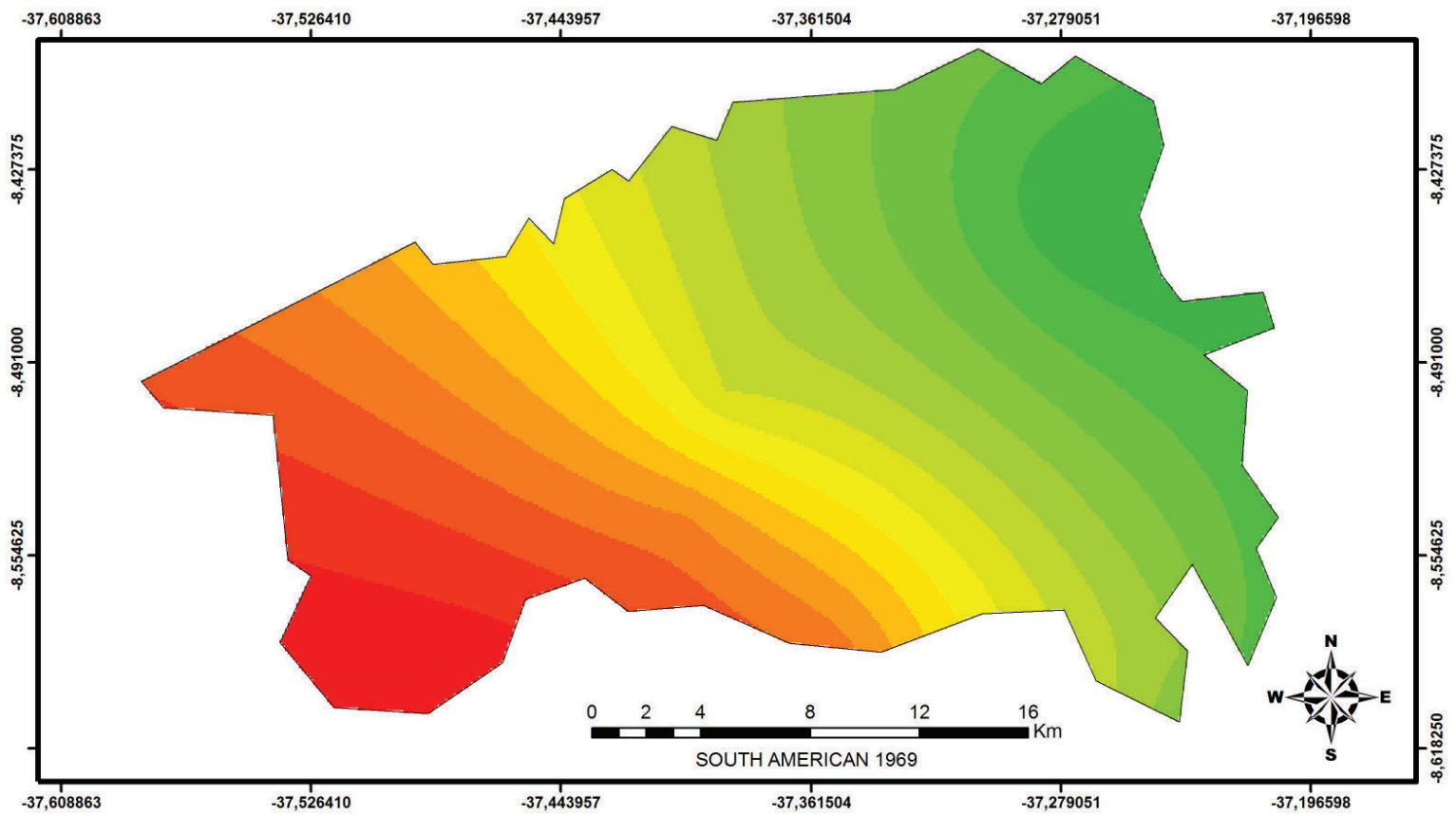

\section{Classes de risco de incêndio - FMA - Ano 2008}

\begin{tabular}{|c|c|c|c|c|}
\hline $13,61-14,52$ & $16,35-17,25$ & $19,08-19,98$ & $21,81-22,71$ & $24,53-25,43$ \\
\hline $14,53-15,43$ & $17,26-18,16$ & $19,99-20,89$ & $22,72-23,61$ & $25,44-26,34$ \\
\hline $15,44-16,34$ & $18,17-19,07$ & $20,9-21,8$ & $23,62-24,52$ & $26,35-27,25$ \\
\hline
\end{tabular}

Figura 3: Risco de fogo durante o ano de 2008

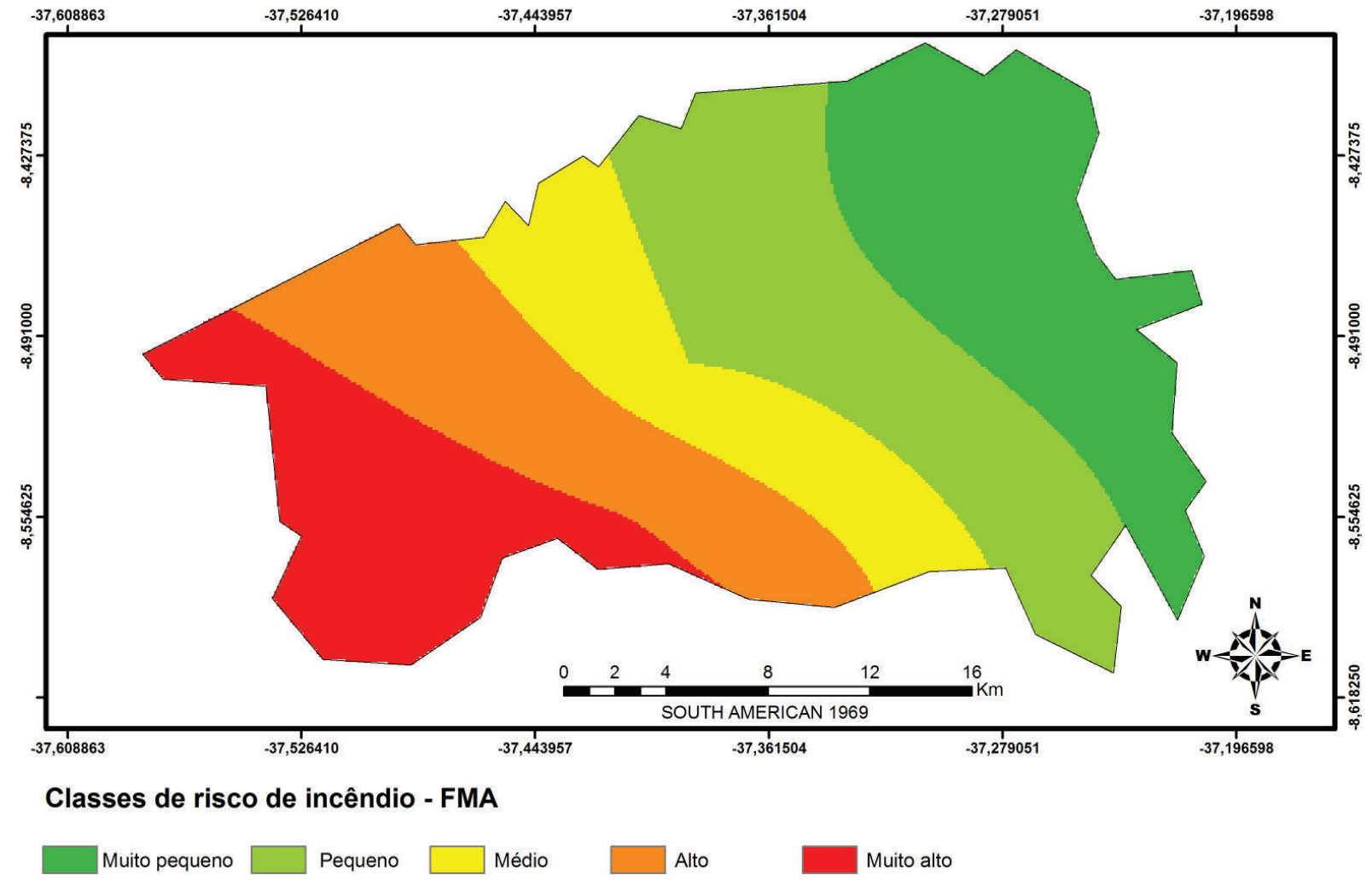

Figura 4: Risco de incêndio florestal espacialmente distribuído 


\section{CONSIDERAÇÕES FINAIS}

Neste estudo foi configurado e testado um sistema para estimar o risco de incêndio no Parque Nacional do Catimbau, na cidade de Buíque, baseado em SIG. Para tal, utilizou-se a integração de métodos de predição de índices de risco de incêndio acumulativo e de produção de mapas com os resultados do índice aplicado.

Observou-se mês a mês o a variabilidade climática (media relativa do ar medida às $13 \mathrm{~h}$ e a precipitação diária) aplicando-as na fórmula Monte Alegre e assim obtendo informações de áreas mais suscetíveis a ocorrência de incêndios florestais. A importância da realização deste trabalho é que através da produção dos mapas temáticos, pode-se identificar quando e onde o risco de incêndio é maior, assim podendo investir de forma eficaz num sistema eficiente de combate aos incêndios.

O sistema utilizado para determinação do diagnóstico diário específico para o risco de fogo mostrou-se ser bastante aceitável. Os índices evidenciam boa correlação com ocorrências verificadas in loco de focos de fogo, confirmando a sua utilidade na identificação de áreas de risco potencial. Entretanto, sugere-se que alguns esforços sejam tomados para aumentar a precisão da estimativa do risco de fogo, tais como uma base de dados histórica de registros de ocorrências de focos de fogo mais extensa e precisa para ter uma relação mais robusta entre valores de índice de risco de incêndio.

As informações cedidas pela brigada contra incêndios florestais (IBAMA), não são documentadas, isto é, são apenas relatos dos moradores do Distrito de Catimbau que periodicamente são recrutados a fazer parte desde grupo de brigada, por não serem documentadas é difícil de trabalhar com elas como evidencias de ocorrência de incêndios, portanto foram observados os focos de antigos incêndios in loco e as informações de focos de calor do satélite NOAA-AVHRR.

Os dados a respeito de incêndios florestais no Parque Nacional do Catimbau são escassos, e para alguns períodos até inexistentes, por isso também a importância deste trabalho, para que sirva como fonte de informação para uma futura construção de bancos de dados de ocorrência de incêndios.

Os resultados adquiridos através da aplicação do índice na construção dos mapas temáticos mostram o quão alto é o nível de suscetibilidade nas porções sudoeste do Parque, e são também justamente estas áreas as que apresentam menor proteção, por conta da sua localização, já que o núcleo de apoio ao parque encontra-se na porção leste do parque, mas precisamente no distrito de Catimbau, e o mesmo não conta com equipamentos de trabalho especifico (carro, GPS, torres de observação etc.).

\section{AGRADECIMENTOS}

À Fundação de Amparo à Ciência e Tecnologia de Pernambuco (FACEPE), pela concessão de bolsa de mestrado. Ao Grupo de Estudo Climatologia Tropical e Eventos Extremos (TROPOCLIMA) e ao Grupo de Sensoriamento Remoto (SERGEO), ambos do Departamento de Ciências Geográficas da UFPE, pelo apoio à pesquisa.

\section{REFERENCIA BIBLIOGRÁFICA}

ANTUNES, M.A.H. Uso de satélites para detecção de queimadas e para avaliação do risco de fogo. Revista do Departamento de Eng. Florestal UFPR. Curitiba, n.25, 2000.

BATISTA, A C. Incêndios Florestais. Revista do Departamento de Eng. Florestal UFRPE. Recife, n. $16,1999$.

BATISTA, A.C.; OLIVEIRA, D.S.; SOARES, R.V. Zoneamento de risco de incêndios florestais para o Estado do Paraná - FUPEF, Curitiba, Série Técnica. vol.2, n. 2, 2002. p. 86 - 94.

BEUTLING, A.; BATISTA, A.C.; SOARES R. V. Quantificação de material combustível superficial em reflorestamentos de araucária angustifólia. Revista do Departamento de Eng. Florestal UFPR. n. 27, 2005. 
BOSCHETTI, L.; BRIVIO, P. A.; GREGOIRE, J. M. The use of Meteosat and GMS to detect burned areas in tropical environments. Remote Sensing of Environment. Amsterdam, n. 85, 2003.

CHUVIECO, E. Y M.P. MARTÍN. Nuevas Tecnologías para la estimación del riesgo de incendios forestales. Consejo Superior de Investigaciones Científicas. Madrid, n. 109, p. 112 - 120. 2004.

CHUVIECO, E.; SALAS, F.J.; VEJA, C. Remote sensing and GIS for long term fire risk mapping. Periodico de la Universidad de Alacalà. Alacalá, n. 91, 1997.

FERRAZ, S.F.B.; VETTORAZZI, C.A. Mapeamento de risco de incêndio florestal por meio de sistema de informações geográficas (SIG). Scientia Florestali. Millan, n. 39, 1998.

GISBORNE, H.T. The principles of measuring forest fire danger, Journal of Forestry, California, n. 42, 1936. MACEDO, W. SARDINHA, A. M. Fogos Florestais, Revista da Universidade de Trás-os-Montes e Alto Douro. Lisboa, n. 45, 1985.

MANZI, A.O. Experimento de Grande Escala da Biosfera-Atmosfera na Amazônia. Brasília: 2005, http://lba.cptec.inpe.br/lba/ Acessado em: 18/08/2008.

MEDEIROS, M.B. Efeitos do fogo nos padrões de rebrotamento em plantas lenhosas, em campo sujo. Tese (Doutorado em Engenharia Florestal). 2002, p. 122. Universidade de Brasília, Brasília, 2002.

MUTCH, R.W. Wildland. Fires and Ecosystems - A. Hypothesis. Ecological Society of America. Washington, v.51, n. 6, 1970.

OLIVEIRA, D. S. Um novo índice de perigo de incêndios florestais para o Estado do Paraná-Brasil. Dissertação, (Mestrado em Ciências Florestais Setor de Ciências Agrárias) 2002, p.113. Universidade Federal do Paraná, Curitiba, 2002.

PHILLIPS, C., NICKEY, B. The Concept of Spatial Risk and Its Application to Fire Prevention. Fire Managent Notes, Idaho n. 39, 1978.

RAZAFIMPANILO, H.; FROUIN, R.; IACOBELLIS, S. F.; SOMERVILLE, R. C. J. Methodology for estimating burned area from AVHRR reflectance data. Environ Remote Sens. Amsterdam, n.46, 1995.

SAMPAIO, O.B. Estudo comparativo de índices para previsão de incêndios florestais na região de Coronel Pacheco, Minas Gerais, Viçosa. Dissertação, (Mestrado em Ciências Florestais) 1991, p. 88, Universidade Federal de Viçosa, Viçosa, 1991.

SOARES, R.V. Índice de Perigo de Incêndio. Revista do Departamento de Eng. Florestal UFPR. Curitiba, n. 13, 1972.

SCHULTZ, M. Use of ATSR fire count data to estimate the seasonal and interanual variability of biomass emissions. Atmospheric Chemistry and Physics. Göttingen, n. 50, 2002.

Trabalho enviado em julho de 2011 Trabalho aceito em agosto de 2011 